titres against measles in patients with MS, as well as the delay in developing measles during childhood in these patients, ${ }^{21}$ seems to indicate a high resistance against that virus. Panelius et al ${ }^{21}$ showed not only that patients with MS contracted measles later than their siblings but also that men with MS tended to contract measles at an earlier age than women with the disease. The resistance of patients with MS to other types of microorganisms has also been reported and supports the idea that such patients are higher responders to these micro-organisms.

If this hypothesis is true, serological studies might confirm the other observation of Panelius et al that histories of rheumatic fever were slightly less common in patients than in their siblings. This suggests that patients with MS have a higher resistance towards these micro-organisms. Nevertheless, nothing rules out the possibility that measles virus is directly related to the cause of the disease. The observation of Zabriskie et $a^{22}$ that there is a decreased cell-mediated response to paramyxovirus in patients with MS conflicts with this view, and this finding should perhaps be regarded as being similar to the abnormal PPD reaction found in patients with MS a few years ago. ${ }^{3-5}$ These findings suggest that research, rather than focusing on a few exciting viruses or slow virus infections, should examine more closely the specific immune mechanism of patients with $M S$ and its reaction to many types of infection.

The control of the immune response by genes related to the expression of the HLA antigens may be relevant. It has been well documented in animals that the genes controlling the expression of the transplantation antigens are closely linked to those controlling the expression of the immune response. Patients with MS have a higher incidence of HLA-3 and W 18 antigens than the normal population. ${ }^{17-19}$ The association of HLA-3 and W 18 in $30 \%$ of our patients compared with only $1.5 \%$ of 637 kidney recipients is another interesting observation, and we are currently investigating the relation between this association and the evolution of the disease. Patients with MS have a mixed lymphocyte culture determinant in common, identical with that associated with the HLA-7 and W 18 in normal people. ${ }^{23}$ All these results reinforce the increasing evidence that the locus similar in the mouse to the well-known lactate dehydrogenase (LD) locus that controls the expression of the immune response, abnormally controls this response in patients with MS.

We thank Dr E Potworowski and his technicians for the lymphocyte typing and Dr St-Hilaire and the neurologists from Notre Dame Hospital of Montreal for their clinical help.

This work was supported by a grant from the Multiple Sclerosis Society of Canada.

\section{References}

${ }^{1}$ Kabat, E A, Moore, D H, and Landow, H, fournal of Clinical Investigation, 1942, 21, 571.

2 McAlpine, D, Lumsden, C E, and Acheson, E D, Multiple Sclerosis, 2nd edn. Edinburgh and London, Churchill Livingstone, 1972.

${ }^{3}$ Smith, H V, Hughes, I E, and Hunter, G, fournal of Neurology, Neurosurgery and Psychiatry, 1961, 24, 101.

${ }^{4}$ Marshall, J, and O'Grady, F, fournal of Neurology, Neurosurgery and Psychiatry, 1959, 22, 277.

${ }^{5}$ Miller, H, et al, fournal of Neurology, Neurosurgery and Psychiatry, 1961, 24, 118.

${ }^{6}$ Lamoureux, G, and Borduas, A G, Clinical and Experimental Immunology, $1966,1,363$.

${ }^{7}$ Adams, J M, and Imagawa, D T, Proceedings of the Society for Experimental Biology and Medicine, 1962, 111, 562.

${ }^{8}$ Lamoureux, G, et al. In preparation.

${ }^{9}$ Lamoureux, G, et al, Neurology, 1975, 25, 537.

10 World Health Organisation, Respiratory Virus Disease, Technical Report Series No $170, p$ 48. Geneva, WHO, 1959.

11 Lamoureux, G, et al, Annals de l'Institut Pasteur, 1970, 118, 562.

12 Jondal, M, Holm, G, and Wigzell, H, fournal of Experimental Medicine, 1972, 136, 207.

${ }_{13}$ Wybran, J, and Fudenberg, H, fournal of Clinical Investigation, 1973, 52, 1026.

14 Lamoureux, G, et al, Union Medicale du Canada, 1972, 101, 674.

${ }^{15}$ Lamoureux, G, et al, La Vie Médicale au Canada Français, 1974, 3, 479.

16 Jersild, C, Svejgaard, A, and Fog, T, Lancei, 1972, 1, 1240.

17 Jersild, C, et al, Tissue Antigens, 1973, 3, 243.

${ }_{18}$ Naito, S, et al, Tissue Antigens, 1972, 2, 1.

19 Bertrams, J, Kuwert, E, and Liedtke, U, Tissue Antigens, 1972, 2, 405.

${ }^{20}$ Currier, R D, et al, Neurology, 1974, 24, 748.

21 Panelius, M, et al, Acta Neurologica Scandinavica, 1973, 42, 89.

22 Utermohlen, V, and Zabriskie, J B, fournal of Experimental Medicine, 1973, 138, 1591.

${ }^{23}$ Jersild, C, et al, Transplantation Proceedings, 1973, 5, 1791.

\title{
Intestinal absorption in normal Indian and English people
}

\author{
M D HELLIER, A N RADHAKRISHNAN, V GANAPATHY, A GAMMON, S J BAKER
}

British Medical fournal, 1976, 1, 186-188

\section{Summary}

The absorption of glycine, glycylglycine, water, and electrolytes was studied by intestinal perfusion in normal Indian and English people. Compared with the English people the Indians showed impaired absorption of all four substances. In the Indians the absorption of glycine and glycylglycine was impaired to the same extent, so

Wellcome Research Unit, Christian Medical College Hospital, Vellore 632004, Tamil Nadu, India

M D HELLIER, MD, MRCP, senior medical registrar (present address: Department of Gastroenterology, St Thomas's Hospital, London SE1 $7 \mathrm{EH})$

A N RADHAKRISHNAN, PHD, professor of biochemistry

V GANAPATHY, MSC, research fellow

A GAMMON, MB, BS, research fellow

S J BAKER, MD, FRACP, professor of medicine that the kinetic advantage of glycylglycine as compared with glycine was preserved. The reduced absorption in the Indians may be the functional counterpart of the minor morphological changes seen in the jejunal mucosa of people living in southern India.

\section{Introduction}

Normal Indian and English people differ in the structural appearance of their small intestinal mucosa. ${ }^{12}$ Evidence of a functional difference, however, rests principally on studies of xylose and fat excretion, ${ }^{3}{ }^{4}$ which are at best indirect methods of quantifying absorption. We have therefore used the more direct method of intestinal perfusion to quantify and compare amino-acid and dipeptide absorption in apparently normal Indian and English people.

\section{Subjects and methods}

The English people (six men) had been studied previously in London by MDH. ${ }^{5}$ The Indians $(10$ men) were admitted to this unit 
for metabolic studies. All were either normal volunteers or patients admitted with minor gastrointestinal symptoms, and in none was there any suspicion or evidence of small-bowel disease. In all cases the nature of the investigation was explained and the subject's consent obtained. The age distribution was comparable in the two groups. Absorption studies with fat, xylose, and vitamin $B_{12}$ and jejunal biopsy were carried out as described. ${ }^{6}$

Perfusion of the proximal $30 \mathrm{~cm}$ of jejunum was carried out with a double-lumen tube incorporating a proximal occlusive balloon. ${ }^{5}$ The perfusion solutions were glycine $20 \mathrm{mmol} / \mathrm{l}$ and glycylglycine $10 \mathrm{mmol} / 1$ containing polyethylene glycol $4 \mathrm{~g} / 1$ made isotonic with saline and with the $\mathrm{pH}$ adjusted to $7 \cdot 0$. Solutions were perfused at a constant $15 \mathrm{ml} / \mathrm{min}$. For each solution, after a 30 -minute equilibration period three 10-minute collections were made from the distal end of the test segment. All samples were collected on ice. Samples for dipeptide analysis were immediately acidified to $\mathrm{pH} 1 \cdot 0$. All samples were centrifuged to removed particulate matter and stored at $-20 \mathrm{C}$ to await analysis.

Amino-acids and dipeptides were measured by paper chromatography, ${ }^{7}$ polyethylene glycol was measured by the method of Hyden, ${ }^{8}$ and electrolytes were determined by standard methods. When glycylglycine absorption was being studied free glycine accumulated in the perfusate. This free glycine was assumed to have been liberated by hydrolysis at the brush border and was therefore subtracted from the amount of glycylglycine that had disappeared from the perfusate to determine the amount absorbed. Absorption rates were calculated using standard formulae. ${ }^{5}$

\section{Results}

In the English people the absorption of fat and xylose was normal. None of the Indians had steatorrhoea or vitamin $\mathbf{B}_{12}$ malabsorption, but three had a reduced five-hour urinary xylose excretion $(13 \%$, $17 \%$, and $22 \%$ ). The jejunal biopsy specimens from the Indians were similar to those from apparently healthy Indians described previously. ${ }^{2}$

Amino-acid and dipeptide absorption-Significantly less glycine $(P<0.0005)$ and glycylglycine $(P<0.0025)$ was absorbed by the Indians than by the English people (fig 1), the mean values being $31 \%$ less in each instance. This suggested that the uptake mechanisms for both the free amino-acid and the dipeptide were equally affected.

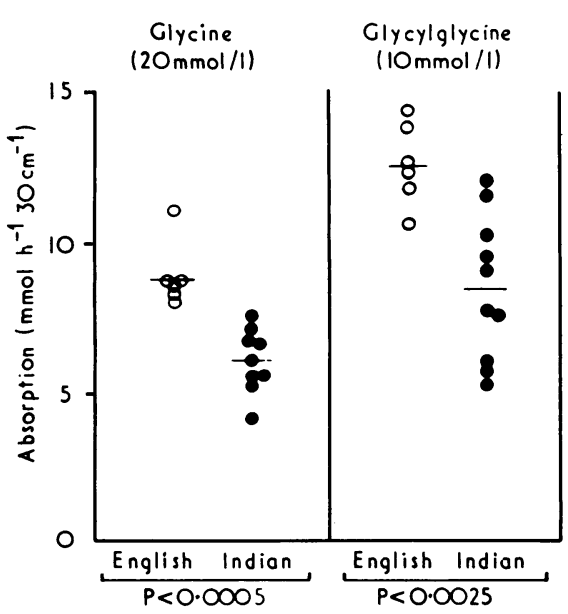

FIG 1-Absorption of $20 \mathrm{mmol}$ glycine and $10 \mathrm{mmol}$ glycylglycine in normal English $(O)$ and Indian (O) people. Absorption expressed as mmol glycine absorbed per hour over $30 \mathrm{~cm}$ jejunum. Horizontal lines represent means.

In both groups the absorption of glycine when presented as the dipeptide was significantly greater than when presented as the free amino-acid ( $P<0.01$ in both groups). This kinetic advantage, as measured by the percentage increase in mean glycine absorption, was the same in the Indian group $(30 \%)$ as in the English group $(29 \%)$ despite the overall reduction in absorptive capacity in the Indians.

Sodium and water absorption-Sodium and water absorption in the presence of both glycine and glycylglycine was reduced in the Indians, the reduction being statistically significant in all cases except for the absorption of sodium from glycine solutions (fig 2). Chloride move-

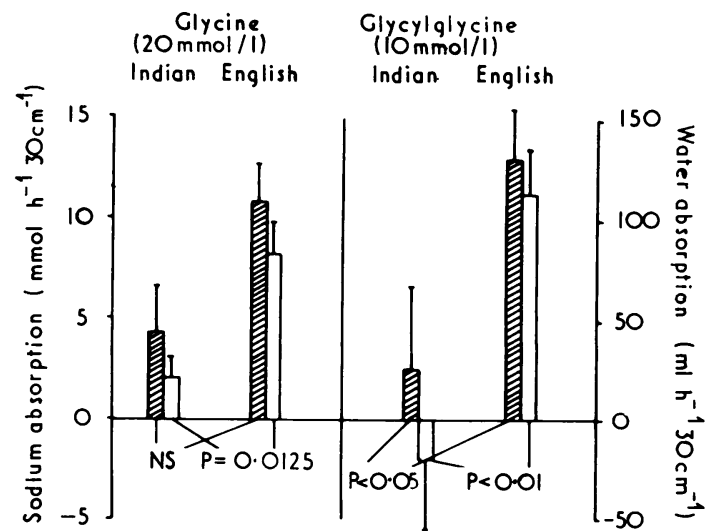

FIG 2-Absorption of water $(\square)$ and sodium (Z) from solutions of glycine and glycylglycine in normal Indian and English people. Columns represent means, and vertical lines and bars represent standard deviations. NS $=$ Not significant.

ment in all cases paralleled sodium movement and is not considered separately. To some extent the reduction of sodium and water absorption may be explained on the basis of the reduction in aminoacid and dipeptide uptake in the Indians; however, the sodium and water absorbed per mole of non-electrolyte by the Indians was still less than that in the English group. As these observations were based on net fluxes it is not possible to say whether the changes were due to an alteration of the sodium/amino-acid interaction at the uptake stage or to increased sodium efflux into the lumen.

No correlations were found between the results of the perfusion studies and the tests of absorption or the jejunal histology.

\section{Discussion}

The Indians in this study were similar in all respects to normal southern Indians investigated previously. ${ }^{4}$ Earlier studies had suggested that normal Indian people do not absorb xylose and fat as well as normal Western people do. ${ }^{34}$ This study, employing a direct measure of absorption, with identical techniques in both groups, unequivocally establishes the lower absorptive capacity of the upper jejunum of Indians for aminoacids, dipeptides, water, and electrolytes as compared with normal English people. This reduced absorption may be genetically determined, as is the case with lactose absorption and the reduced lactase levels found in normal Indians. ${ }^{9}$ It is more likely, however, that it is acquired and is a result of the process responsible for the mild histological abnormalities seen in these patients and which are widely prevalent in the tropics.

Theoretically several factors may be responsible for these functional and structural changes. ${ }^{2}$ Parasitic infestation may cause intestinal damage, but no parasites were found in any person in this study. Intraluminal bacteria may produce absorptive defects, as in the stagnant-loop syndrome. Bacteria are more numerous in the upper small intestine of Indian people than in people in the West, but histological changes do not parallel bacterial counts. ${ }^{10}$ Moreover, bacteria are much more numerous in the lower small bowel, where histological changes are less pronounced. Of course, qualitative studies might indicate the presence of particular organisms within the jejunum capable of producing specific mucosal toxins, but none have been identified. Viral isolates were obtained from $58 \%$ of faecal specimens collected at random from southern Indian children, ${ }^{11}$ and some $90 \%$ of apparently healthy southern Indian adults excrete viruslike particles in their stools, suggesting a continued viral infection of the gastrointestinal tract. ${ }^{12}$ Such a continuing infection may result in functional damage.

Finally, nutritional deficiencies may affect intestinal structure and function. Protein deficiency has been suspected as a cause of structural change but available data are inconclusive and uncontrolled. Patients in temperate regions with hypoproteinaemia due to dietary or renal causes have normal intestinal histology. ${ }^{13}{ }^{14}$ Iron, vitamin $B_{12}$, and folate deficiencies have all 
been incriminated as responsible for small-intestinal mucosal change, but these deficiencies were absent or only marginal in the present series.

If the reduced absorptive capacity of the upper jejunum in Indians is representative of the function of the whole small intestine, this finding may be of considerable nutritional importance, particularly for populations with an inadequate or only marginally adequate diet. Furthermore, if the observed defect of absorption is acquired, elucidation of the causative factors and their elimination could make a substantial contribution to improving the nutritional status of the community.

$\mathrm{MDH}$ was in receipt of a research grant from the endowment fund of St Thomas's Hospital, London. We wish to thank Mr R Jacob, Miss K M Roshini, and Miss N Indrani for technical help. The Wellcome Research Unit is supported by the Wellcome Trust in association with the World Health Organisation.

Requests for reprints should be sent to Professor S J Baker.

\section{References}

${ }^{1}$ Baker, S J, et al, in Intestinal Biopsy, Ciba Foundation Study Group, No 14, ed G E W Wolstenholme and M P Cameron, p 84. London, Churchill, 1962.

2 Baker, S J, Pathologia et Microbiologia, 1973, 39, 222

${ }^{3}$ Baker, S J, Jacob, R, and Mathan, V I, Indian fournal of Medical Research, $1971,59,1869$.

4 Baker, S J, and Mathan, V I, American fournal of Clinical Nutrition, 1972, 25,1047

${ }^{5}$ Hellier, M D, 'et al, Gut, 1972, 13, 965.

6 Mathan, V I, Swarnabai, S, and Baker, S J, Indian fournal of Medical Research, 1973, 61, 714.

${ }^{7}$ Das, M, and Radhakrishnan, A N, Biochemical fournal, 1973, 135, 609.

${ }^{8}$ Hyden, S, Kungligia Lantbrukshögskolans Annaler, 1955, 22, 139.

Swaminathan, N, et al, Clinica Chimica Acta, 1970, 30, 707.

10 Bhat, P, et al, Gastroenterology, 1972, 62, 11.

11 John, T J, personal communication, 1972.

12 Mathan, M, et al, Lancet, 1975, 1, 1068.

13 Gough, K R, et al, Quarterly fournal of Medicine, 1963, 32, 243.

14 Jansen, H, Jarnum, S, and Hansen, J P H, Nephron, 1966, 3, 209.

\section{Bleomycin in advanced squamous cell carcinoma: a random controlled trial}

\section{Report of Medical Research Council Working Party on Bleomycin*}

British Medical fournal, 1976, 1, 188-190

\section{Summary}

Bleomycin was compared with conventional cytotoxic drugs in the treatment of 70 patients with advanced squamous cell carcinoma; the primary deposit was in the head and neck in 50 patients and in the perineum or skin in 20. Thirty-four patients received bleomycin while 36 received other cytotoxic drugs. No significant difference was detected between the two groups either in the proportion showing tumour regression or in the survival rates. If bleomycin is to advance the treatment of squamous cell carcinoma it can be only in combination with other drugs or with radiotherapy.

\footnotetext{
* Members of the working party were:
}

Institute of Radiotherapeutics, Glasgow G11 6NT

K E HALNAN, MD, FRCP," director and chairman of working party

T B BREWIN, MRCP, FRCR, consultant in radiotherapy and oncology

Medical School, Cambridge CB2 2 QH

N M BLEEHEN, FRCP, FRCR, professor of clinical oncology

South Wales and Gwent Radiotherapy Service, Cardiff CF4 7XL

T J DEELEY, MB, FRCR, director

Department of Laryngology and Otology, University of London, London WC1

D F N HARRISON, MD, MS, professor

MRC Statistical and Research Services Unit, London WC1E 6AS

C HOWLAND, BSC, member of staff

A L JOHNSON, PHD, member of staff

Royal Infirmary and Western General Hospital, Edinburgh EH3 9YW G L RITCHIE, FRCS, FRCR, consultant in radiotherapy and oncology

Christie Hospital and Holt Radium Institute, Manchester M20 9BX I D H TODD, MRCP, FRCR, consultant in radiotherapy and oncology and secretary of working party

\section{Introduction}

An uncontrolled trial has confirmed that bleomycin has significant clinical activity, but the response of patients with various types of tumours to bleomycin alone was poor. ${ }^{1} \mathrm{We}$ therefore conducted a randomised controlled trial comparing bleomycin with other cytotoxic drugs to determine the drug's effectiveness in treating patients with squamous cell carcinoma.

\section{Patients and methods}

Patients with well-differentiated squamous cell carcinoma in the mouth, pharynx, larynx, oesophagus, perineum, or skin were eligible for entry to the trial. The tumour had either to be too far advanced for an attempt at curative surgery or radiotherapy or, as was more common, to have recurred after surgery or radiotherapy. Only those patients who had a reasonable expectation of life and were easily accessible for treatment and follow-up were selected.

On entry to the trial, after inquiry by telephone to the MRC Statistical Research and Services Unit, the patient was given bleomycin treatment or treatment with other drugs. Patients were randomly allocated to the two treatment groups after stratification according to the treatment centre, the sex, and the following subsites within the sites mentioned above: buccal mucosa, gums, hard palate, floor of mouth, tongue, oropharynx, nasopharynx, pyriform sinus, postcricoid, posterior pharyngeal wall, supraglottic, glottic, or subglottic regions, cervical oesophagus, intrathoracic oesophagus, vulva, penis, scrotum, and anal orifice.

In the bleomycin group our intention was to give bleomycin $30 \mathrm{mg}$ intramuscularly twice a week to a total of $300 \mathrm{mg}$ if this was tolerated. We allowed a reduction in dose for extreme age in a few patients, and the dose was modified for other reasons too (see table II). Most patients were treated as outpatients. In the other group the clinician in charge used the cytotoxic drug and regimen of his choice. In both groups further chemotherapy or radiotherapy could be given after failure of treatment. Patients in both groups received analgesics, blood transfusions, surgical procedures to relieve pain, or steroids as considered necessary. Routine chest radiographs and haematological and biochemical investigations were carried out on all patients before, during, and after treatment.

\section{Results}

Seventy patients entered the trial; their distribution between treatments according to tumour site, sex, and age is shown in table I. 